\title{
The Effectiveness of Facebook as a Marketing Tool \\ (Saudi Arabia case study)
}

\author{
Hadeel AL-Ghamdi \\ Nora Al-Hadban \\ Thekra Al-Hassoun \\ Supervised by: \\ Prof. Randa Hamdi
}

Abstract

This research was written to discover the future trends in new media and social networking .The researchers have taken a personal interest in the developments of Web 2.0 platforms after noticing the impact they have made on society on a global scale as well as in our own daily life. The advances in this technology have altered the way individual users and organizations can communicate with each other.

In this study of the social network sites we will concentrate on Facebook and its effectiveness as a tool of marketing in the Saudi population because recently it gained enormous popularity for marketing communications. Facebook especially describes itself as the perfect marketing tool because its developers have created an advertising system which allows businesses to use the information of each Facebook user for targeted advertising. Facebook provides the ideal platform for direct communication between organizations and customers. Marketing on social network sites has to follow new rules and principles and each organization has to clearly determine if social media marketing is appropriate for them or not.

Through extensive research and analysis, the researchers intended to find if the Facebook is an effective marketing tool in Saudi Arabia where marketers can reach and influence targeted consumers.

\section{Keywords:}

Facebook; Marketing effectiveness; Marketing tool.

\section{Council for Innovative Research}

Peer Review Research Publishing System

\section{Journal: International Journal of Management \& Information Technology}

Vol. 10 No. 2

editorsijmit@gmail.com

www.ijmit.com/ois 


\section{Introduction}

Communication between individual and organization have change dramatically, since the emergence of the Internet in the late 20th century, within the Web 2.0 , there is the creation of platforms that connect people together (social networks), the ability to produce and then share content with others (social media) so audiences and content generators all over the world became connected at all hours of the day through the World Wide Web, which is collection of hypertext sites that is available for users to connect to its host network called the Internet. The possibilities of the Web exceed such "traditional" channels as, pagers, newspapers, televisions, radios and telephones. This form of technology allowed the creation of new communities and instantaneous, or high-speed, communication. It was used by users for several things like personal hobbies, research, entrepreneurial endeavors, business operations, news delivery, entertainment and more.

The increase in reliability and availability of the internet in the last 10 years alone has significantly changed how people of all ages and occupations have used it. Online communities and forums began to form, with themed chat rooms, message boards, and mass email or fan groups established on such website platforms as Yahoo! and AOL almost as soon as the Web was born.

Prior to the broad scale introduction and availability of the internet to the public, traditional forms of marketing (public relations, advertising, branding and messaging) were channeled through slower mediums, the explosion of media channels (The internet), however, has allowed both individuals and organizations to post content, and react to each other's content, creating a matrix of multi-directional communication rather than the one-way messages consumers received in the past. In this way, the internet provides an intricate web of audiences to filter through before delivering effective messaging and placing control in customers' hands or, more accurately, in their mice.

In the past online marketing took the form of spamming (sending unwarranted messages out to mass audiences) as well as unsophisticated attempts at online advertising. As time-shifted there were myriad ways in which communication professionals can, and are, connecting with their key audiences. The challenge is in creating the ideal social media and online atmosphere in which these audiences will be responsive and build the kinds of relationships that will lead to the achievement of communication or business objectives. However, because billions of users access the internet every day, businesses must be careful and aware that on the internet, a little information - or a lot of information - can go a very long way and spread all over the web pages and still have little or no effect .

Online communities in which users interact for casual, personal or professional interaction are also known as social networks (some of which include a collaboration of users all over the world). Social networks are becoming accessible from cellular phones and public internet sites (e.g., schools, airports), not only available through the internet on personal computers.

A number of social networks are available but the largest one is Facebook, and it will be the focus of this research. Facebook provides several uses to fulfill the needs of its consumer users, and functions much like an online social media portal.

Millions use Facebook services and applications, so organizations of all types create corporate accounts and create profiles to reach users. Even though Facebook began as a network for a limited number of U.S. university students, it is now accessible to users of any age, and most of its registered users are located outside the United States.

According to the phenomenal growth of Facebook, our questions are if it is a viable and effective channel for organizations seeking to reach their audiences. In this study, we will examine four main areas to determine Facebook's ability to serve as a viable and effective marketing platform for businesse

First, we will analyze the research, suggestions and theories of industry experts and literature. These ideas will help to shape the evidence for the effectiveness of the social media as marketing tools in general and the Facebook in particular.

Second, we will analyze what organizations and businesses are doing online to market to users. Moreover, we will suggest some strategies that are most utilized today to improve an organization's reputation or branding; or to sell a product, service or idea.

Third, we will measure the effectiveness of an organization's presence on Facebook in particular. What are the benefits they really getting out of it? What does the average Saudi Facebook user actually think about its presence on that platform?

Finally, we will suggest how organizations can create an effective "social marketplace." That is, what is the best online venue for marketing communications with consumers who currently active in social networks and other forms of social media. This includes Saudi consumers of all demographics but targeted to those who are currently active online or intend to become more active in the next 5-10 years. Based on user responses and research analysis, these recommendations will serve as a guide for how organizations can best improve their current operations and proceed for the future.

\section{The Aim of the study:}

Throughout the course of this research, the intended goal is to determine the best social network market for individuals and organizations to reach their target audiences for the purposes of delivering messages about a product, service or idea; we will examine the Facebook's ability to serve as a viable and effective marketing tool for targeting customers in Saudi Arabia, delivering messages about a product, service or idea. The problem can be expressed by asking the following question: 
"Is the Facebook considered as an effective marketing tool in Saudi Arabia?"

The overall purpose is to provide a comprehensive analysis of social network sites as a marketing tool with a focus on Facebook. The goal is to determine if Facebook is an effective marketing tool, how organizations can use Facebook for marketing purposes and if users are responding to these initiatives or not.

\section{The significance of the study:}

This study will be extension of the previous researches that studies the effectiveness of the facebook as a marketing tool, the significance of this study is that it will be applied in the Saudi society, it will be helpful to the marketers and business practitioners in Saudi Arabia in understanding the perception of the Saudi customer about using the facebook in marketing. It will also serve as a future reference for researchers on the subject of the effectiveness of the facebook as marketing tool in the Saudi society. And importantly, this research will educate marketers whose working in the Saudi society in deciding on whether investing in facebook will help the company in reaching its marketing goals or not.

\section{Chapter 1: Literature Review}

We can argue that the acceleration of mainstream Web 2.0 platforms start at either 2005 with the creation of YouTube or in 2006 as Laudon \& Traver (2005) has shown when Google purchased YouTube, but either indicates that the information about social media marketing in Web 2.0 is fairly recent and constantly being updated. Additionally, because the internet is such a huge space, it opens the opportunity for large experts within the corporate world, literature and blogs. . Given that some of these experts are more authoritative than others, some of their views and theories make up a foundation for the effective social marketplace.

The research of Universal McCann (2010) was used for its social media results. It is the third of the media giant's global internet surveys. It received feedback from participants' ages 16-54 in 54countries, 37,600 internet users were surveyed with many new markets joining, including the Middle East .In this case, "active" was defined as using the internet at least once per day.

\section{The Demand for Social Media Marketing:}

The first observation drawn from the literature review was that social media offer great marketing potential. For example, In 2010 Universal McCann's survey showed that there are a great increase in usage from $57 \%$ to almost $70 \%$ of active Internet users belong to a social network, making it the premier platform for creating and sharing content. This creates potential for organizations that can find a way to get involved in this content. What we have discovered in literature review of our research is that social media participation among active internet continues to vary widely, in some countries blogging is or was top of the tree, in others it is or was uploading video, for example. In all markets the use of social networks has been rising steadily - and in some cases very rapidly indeed. Similarly the latest research project finds that the motivations for blogging, joining a social network, uploading a video or a photo are not only very different at a global level but that individual countries and regions also have a different take on the value, appeal and utility of each platform. The combination of social demand and platform understanding will give us the clear insight to create successful social media programmers. Further data that is drawn from Universal McCann's survey indicates that several other factions of Web2.0 are also universally important at the same time:

- In 2009 using social networks for 6.4 activities. In 2010 this has now risen to 8. (such activity like sharing videos, organizing groups and events, sharing photos and dating) this trend is decidedly upwards.

- The social networks in 2010 have become the largest source of social interaction, finally outstripping face to face contact in 2009.

- There is declining or stabilizing in reading blogs or blogging in Western countries, but growing in others from $55 \%$ in 2008 to $64 \%$ in 2010.

- The rise of Microblogging which is a great example of a new form of social media that has within an incredibly short space of time, become a mass market activity and increase from 15\% in 2009 to 35\% in 2010 .

The most significant shift in social media over the last few years has been the ability of users to engage in social media via mobile, Alongside these has been the development of a range of easy to use first and third party applications that allow users to engage with their social media platform of choice, such as Facebook or Twitter, they visit their social network profile on average 3.5 times a day, $18 \%$ more often than the average social network user. One of the most interesting things about the mobile social media user is not just the range and frequency of their activity but who they are. You might be forgiven for thinking that the people at the forefront are just the youngest adopters but, in fact, the research shows the higher cost of smart phone ownership and usage means that this audience is certainly at the higher end of the socioeconomic scale. They have a broader age range, more like to be aged $25-34$. They are more likely to be male (63\%), married $(53 \%)$, have a medium to high income (62\%), have a high level of education (65\% have a degree or post graduate qualification). Not only are they a wealthy consumer they are also highly influential. They are more likely work in senior decision making positions within companies (25\%) and are more likely to try products first and influence others in regard to their purchases as reported in Universal McCann's survey (2010).

Consumers are using social media as an important source prior to a purchase decision because they trust other members and their experiences. For instance, we can notice the importance of tourism social media as information tool because the tourism product is intangible and as such cannot be tried out before a purchase (Charlesworth, 2009). In many cases, 
companies see this as the opportunity to deliver messages about a service or product when and where consumers are planning to make a purchase, such as on shopping websites.

Facebook in itself has created a demand for social media marketing. Facebook is one of the largest and fastest growing social network sites, which has developed into a global network. Their goal is to become the operating system of the Internet and to make the world more open and transparent by giving everyone the right to share and connect (Laudon \& Traver, 2008). The amount of web users and social networks such as Facebook is reciprocally beneficial for marketers and consumers. Maria Popova of Brandweek (2007) discusses how the nature of Facebook contributes to the new way consumers view marketing. Popova argues that the site is a tool in our age of "opinionation": "I like this, not that, need this, dump that, want this. Now" The trend has begun to strip marketing to the bare essentials to reveal the all important "What's in it for me?". For marketers, these trends will demand more than just detailing the benefits of a product. Businesses will also have to focus on "interactive benefits" - in Popova's words, "if I choose to engage with your message, what's in it for me?" (Obermire , 2007)

\section{The Social Media Strategy:}

Internet users who participate in social media are able to contact any other user at any time of day if the network is large enough. As a result, users become comfortable with those people in the community of their choosing and often substitute traditional forms of communication with communication via an online medium.

From social network giant Facebook to microblogging site such as Twitter, social media allow users to create strong relationships in entirely new ways. The question is how marketer or organization creates relationships with these users that are keys to the social media marketing strategy. "Justin Smith, editor InsideFacebook.com, [suggests,] 'Be as authentic in your marketing as possible. Inside social networks, trusted referrals are the most powerful marketing message... This is the main value add of marketing in social networks" (Holzner, 2009, P. 8)

This indicates that the organization or marketer must leave room for the consumers to communicate with each other - the main purpose of social networks and other social media platforms- while they are involved in the conversation and create relationships with their consumers. However, intense involvement by an organization can be overwhelming for the audience and not seem genuine. "People don't want to be sold. They are doing their best to avoid commercials. They have pop-up blockers to screen out the ads on the Web that are a distraction." (Weber, 2007, P. 11)

\section{The Research Hypothesis:}

After reviewing the previous literatures we come up with this hypothesis:

Ha: There is a significant relationship between the organization presence in Facebook and its marketing effectiveness.

Independent variable: organization presence in Facebook.

Dependent variable: marketing effectiveness.

In order to measure the marketing effectiveness we will focus on 3 dimensions:

If it helps to build Customer relationship, helps to increase company recognition or awareness, if its motivate customers to buy or effect the purchase decision.

\section{Chapter 2: Methodological}

This chapter presents the methodological procedures used to answer the questions of the study, to achieve the objectives of the study, and by offering the type of study and curriculum and the community of the study sample, and data collection tool, and procedures for validity and reliability, and the study variables and the determinants of the study the three spatial, human and time, and method data collection.

\section{First: the type of study and approach:}

This study is descriptive analytical studies, for consistency with the theme of the study itself and the quality of facts and events to be obtained, the facts that will enable us to obtain accurate information to determine if Facebook is an effective marketing tool, how organizations can use Facebook for marketing purposes and if users are responding to these initiatives or not.

The stage of mainly descriptive research aimed to explore and clarify some of the phenomena that are available and accurate information that applies to this study, as the information around is almost non-existent in the study population, so is the way narrative or descriptive approach most appropriate for this study.

\section{Methodology:}

The purpose of the research is to determine how effective social network sites are as a marketing tool in general and how effective is the Facebook in particular, and to which extent users' purchase decisions are influenced by Facebook applications, pages and advertisements. Therefore, the research question is:

If Facebook is a viable channel for organizations in Saudi Arabia seeking to reach their audiences? 
The methodology of this study is a combination of an in-depth desk research and analysis of the Facebook sites and the outcomes of a conducted quantitative survey with 200 participants in Saudi Arabia to gain their opinions on organization presence on Facebook. In order to partly answer the research questions, the conducted literature review provided a general understanding of social network sites, their members, Facebook's marketing system and applications. We will provide an extensive analysis to the Facebook site in order to understand the way it work and to measure the effectiveness of an organization's presence on Facebook in particular. What are they really getting out of it, What does the average Facebook user actually think about its presence on that platform, and if organization presence in the Facebook could work as a marketing tool. The current state of research about social media marketing is further included in this research to broaden the findings of the conducted survey. A quantitative survey was chosen to measure the correlation between the organization presence in Facebook and its marketing effectiveness that's based in respondent opinion . This survey is based on a descriptive approach, as the primary objective is to test the above-mentioned research questions.

\section{Members of the study:}

Study population consists of the customers in Saudi Arabia.

\section{Sample of the study:}

We choose to study a sample of 200 clients in the Kingdom of Saudi Arabia, and distributed 220 questionnaires to members of the society study, from those 220 clients, 183 respond to the distributed survey. We found that the highest percentage of members of the study sample ranging in age from 16-20 The percentage $(41.0 \%)$, while the members of the study sample aged $21-35$ of representing $(38.8 \%)$ of the members of the study sample, there are $(1.1 \%)$ aged more than 35 years.

\section{Chapter 3: Facebook Analysis}

To test our hypothesis that Facebook is an effective tool to reach consumer a thorough analysis of the site was conducted based on extensive observation of activity, testing of applications and research on expert commentary. The following results of the analysis indicate a positive association of Facebook with social media marketing.

\section{The Social Network Pedestal:}

Facebook is not the only social network in existence but it is increasingly the most Popular. As it mentioned by Arrington (2009) in TechCrunch report that although Facebook is recent and new social media it has been continually growing at an exponential rate and reaching new audience every day around the world. In November 2008 Facebook drew 200 million unique worldwide visitors; more than 1 in 5 people who accessed the Internet that month visited the site. . In December,

222 million people visited the site, a $10.8 \%$ month over month growth rate. $22 \%$ of the total Internet audience went to Facebook in December. Facebook now has nearly 100 million more worldwide users than MySpace, which added 4 million new users in December to 125 million total .The report suggest that the trend will continue, and in January 2010 Facebook has surpass MySpace as the largest U.S. social network.

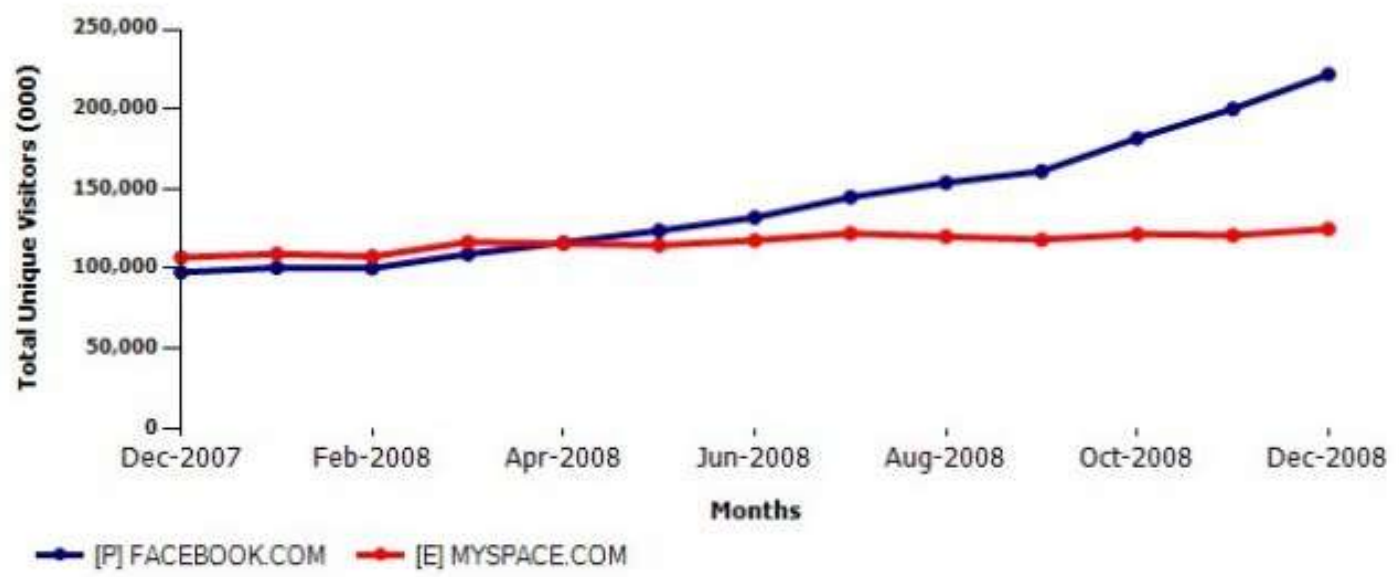

Figure 1: Facebook vs. MySpace Unique Visitors

Also, Lisa Davis (2009) of Time Magazine mentioned that "though Facebook started as an online hub for college students, its fastest-growing demographic is the over- 25 crowd, which now accounts for more than half of the site's 140 million active members." Facebook has more than 800 million active users more than $50 \%$ of the active users log on to Facebook in any given day and average user has 130 friends, about the Facebook activity: more than 900 million objects that people interact with (pages, groups ,Facebook events and community page) average user is connected to 80 community pages, groups and even and on average, more than 250 million photos are uploaded per day according to Facebook statistic today.

Facebook has become successful as social media tool not only because it serves as a space that connecting user more efficiently but it does so by connecting its user to other area that interest them in the web. For example, profiles for 
organization can be found on the site as well as content outside the site that often links back to Facebook with a "share" option. If one reads an article on the website or sees a video on YouTube that he/she wants to send to a friend or post to their Facebook profile, it is possible by clicking the small Facebook icon below the desired content. This is another example of "word of mouse." Sometimes the popularity of several videos, pictures or articles get online buzz and becomes a news story in itself. Sometime a videotaped message did not receive a lot of televised broadcast attention but was getting views on YouTube shortly after it was posted and spread to over myriad blogs and widely circulated on social networking websites.

Facebook Connect is an extension of the Facebook platform that makes it easier for users to take their Facebook account over the Web and share what they do online with friends. By using their account login, registered users can share activities on sites such as CNN and CitySearch with their Facebook profiles they won't have to create separate accounts for every website, just use your Facebook login wherever Connect is available as Zuckerberg (2008) explain in his article.

In addition to Facebook Connect and to simplify how to use Facebook with other social media tools in order to make life a little easier, Smith (2009) stated that some sites have the capable algorithms to synchronize with Facebook in different manners. Facebook Users can sync Facebook events with Google Calendar, sync Twitter updates with Facebook status updates, or import blogs from third-party sites to their Facebook profiles.

In addition, the site's layout has a cleaner look than other social networks, although, MySpace features an extensive amount of well-developed content but looks overwhelmingly cluttered in comparison to Facebook. However, site such as Friendster feature very simple designs but do not offer as much content. And even Facebook continues to add applications and changes in design. Facebook still makes it simple for its users to navigate the site and find organizations. If a design element changes, developers enable optional pop-up explanations of the changes when applicable. The site sets high standards for its users and competitors with high quality services and capabilities. The network constantly finds new ways to improve and meet the needs of its users, providing several uses for individuals, groups and businesses.

\section{Facebook Uses:}

Facebook is a social tool that helps people communicate more efficiently with their friends, family and work colleagues. Founded in February 2004, the company develops technologies to help share information through a social planner, in the form of a digital map similar relations people in the real world. Everyone can register for Facebook and interact with people they know in a trusted environment. Facebook is part of the lives of millions of people around the world. Facebook private equity firm based in Palo Alto, California. It also a useful tool for marketing, corporate communication and public relations. The company in its Facebook Press Room describes itself as a "social utility." Just like any other media channel, Facebook can be used to spread messages and connect to audiences. It is also useful for business-to-business marketing (such as on the career networking site Linkedln) since organizations' posted content is available for anyone to view and share (Weber, 2007).

However, organizations need to be careful, because "in Facebook, the users are in charge, not the marketers." (Holzner, 2009, P.1). Organizations are not in control anymore and need to consider the new power of consumers. Users have the possibility to post negative comments or content on their own profiles or even on an organization's page. The users can repeat this action and it may remain on the page as long as the user who posted the comment or the creator of the page does not delete it. Moreover, the owner of the page has the ability to monitor content and even set restrictions for certain groups of people. In the same time, users also have the power to positively distribute content and information among their peers. It is the features of the website, outlined below, that allow users and organizations to constantly interact and influence each other.

In the year 2009, the Facebook design has been rearranged in order to focus on the news feed, which shows real-time updates and activities of a user's friends that they made on their pages. Not only the news feed is visible on the homepage but also on both user profiles and brand or public pages. The latter two have the same design, developed in March 2009, thus allowing for the average user to better relate to a popular individual. As Smith (2009) stated:

“Facebook's new Pages make it much more natural for marketers to talk and share fresh content with their fans. Because status updates and conversations that Page owners have with their fans on the Page will now be much more prominent, Facebook Pages could become much more important conversational venues around the brand at hand than they have in the past."

A reporter for Advertising Age mentioned that the new layout permit the creators of content to have more power in sharing their information. Brands or public figures using Facebook Pages also have more freedom with the new design to share content or ideas just as well as the average user. This is posted to a friend or fan's homepage, making "sharing" more closely related to "publishing." (Schafer, 2009)

\section{Company Profile Defined:}

A Facebook profile allows all users to display their personal or professional information. A typical profile consists of a picture; the user's name; a "wall"; posted items or notes; videos; photographs; chosen applications and the option to display contact information, profession information, educational and personal interests or views. This is the space where a user represents him/herself, posts new content and connects with others. When one user is connected to another by request, he/she is a Facebook friend of the other and each has customizable privacy options that will allow how much of his/her profile is visible to different groups of people. 
An organization or public figure may also have a profile. Their "friends" may receive information sent to them via messages, wall posts or shared items. In the same time, friends may also post to the profile as well. This is more popular between public figures as a more close connection to users than a Facebook Page. It is only apparent to people with registered Facebook accounts.

\section{Company Page Defined:}

To engage with target customers, Individual Facebook Pages are usually used by groups, organizations, or individual entities such as products, locations or sports teams. Holzner (2009) indicated that the new Facebook pages that has been introduced in November 2007 become more focused on person or brand, this may allows businesses and artists interact with the Facebook users without all the pressure of reaching thousands of friends. They are often obvious to both nonregistered and registered users, this considers as a beneficial marketing strategy that helps the organizations to reach multiple audiences across the internet. Again, it serves as a way for users and companies to interact. Consumers can choose to connect to an organization's page without a request that must be accepted, and is titled as a "fan". Two-way communication is possible, Facebook have created a new form of dialogue between companies and consumers. Traditional forms have been business-to-business (B2B) and business-to customer (B2C), whereas new forms are customer-to-business (C2B) and customer to- customer (C2C) (Chaffey \& Smith, 2005). Moreover, the Facebook Page can also serve as a community within the larger Facebook community by allowing fans to post their own content or opinions to the page while interacting with each other, it is crucial to pay attention to the consumer and their opinions. An interactive Organizations need to interact and communicate with their customers, a Page owner may also post updates regarding what the host organization is doing or offering its consumers, encourage participation, share stories and become a part of the community based on trust and a mutual relationship. (Laudon \& Traver, 2008)

A Facebook page is one of the most effective ways an organization can be engaged with on the network as it can be linked from other websites and even advertised within Facebook itself. This means that through a page, an organization has more opportunities to reach consumers, which possibly leads to increase sharing of information and increase sales.

\section{Application Glossary:}

- News Feed: The main feature of the homepage is that its displays real-time updates of friends' activities within the site. The users have the option to filter of what they would like to see displayed at a given time.

- Wall Posts: the owner of the profile or another user may add Short, unedited messages or multimedia content to a Facebook Profile or Page, or it may be comment on each other's wall posts. A wall is often the most prominent part of a user's profile or page.

- Groups: According to Facebook, groups are "for members of groups to connect, share and even collaborate on a given topic or idea". Groups of users linked by a common theme or interest. A group forms a smaller community within the Facebook community by allowing users to share information, pictures, etc. The group is typically created by individual Facebook users, an organization may also create a group for users that they can join to support a product, cause or the company itself. A Facebook advertising associate, however, stated that the company is attempting to have all organizations switch from creating groups to pages.

- Events: Facebook users can create an event invitation and sent to as many registered users as the creator desires. Two privacy settings are available to set how visible an event will be to others on Facebook. User can also control how the content is shown on the invite and the ability for guests to invite others to the event. This features used by organizations to announce a launch, product sale or special event. It can be publicized to all of Facebook, a specified group of friends or one regional network. For example, some restaurant chains, such as MacDonald's, will use Events to announce a new meal or the opening of a new restaurant in a certain town.

- Discussion boards: This feature can be enabled on many types of websites, allowing users to post questions, ideas, or comments in order to get responses and prompting a discussion. This is a useful application to create an interactive environment and to get feedback on a topic.

- $\quad$ Pictures: Users can add a visual element to Facebook profiles, pages, groups and event invitations, or they share it among others. If an organization uses one of these applications, visual representation is always an advantage.

Some observers advise caution regarding the use of these tools as Holzner (2009) indicates: "Creating your own group can get quite a buzz about your brand. But as with all Facebook marketing, you have to provide interesting content, not just an ad message." (p.45). As stated earlier, consumers do not want to be sold, especially in (what can be) a personal environment.

\section{How to Use Facebook Efficiently:}

Businesses can implement several strategies to use Facebook efficiently.

To navigate among social networks, relationships and content are important. To build a relationship there is two-step process. First, an organization must convincingly tie its brand or main source of communication to its Facebook persona, using interesting and engaging content. Second, an organization needs to stimulate two way communications in which it is actively involved.

Most businesses and organizations have online presence even if only through a corporate website before establishing a presence on Facebook. One way to raise awareness among multiple audiences and encourage traffic among different sources of information is linking an article, product or webpage to a Facebook page or application. As found in the survey 
that we conduct, several consumers care to know that a company has a relationship with Facebook and what its role is on the site.

The relationship between company and audience allowing consumers the opportunity to feel more connected to a brand, cause or product when in communication with one or more people representing the organization. Creating this relationship can increase affinity and credibility. While organizations should be proactive in getting their message out on Facebook, they should wait for the user to reach out first by responding to a posted application, ad or message. "What visitors really want is content that first describes the issues and problems they face and then provides details on how to solve those problems. Once you've built an online relationship, you can begin to offer potential solutions that have been defined for each audience." (Scott, 2007, p. 33)

Finally, to become efficient marketers on Facebook, organizations should also use various other types of content. Online advertising is primarily displayed through banner ads bordering the sides of each page of the website. Many of them are based on an individual user's preferences gathered from other sites visited or links clicked within Facebook. Organizations can even gather market research data by conducting targeted polls on the site based on demographics (Schroeder, 2009) (i.e. Saudi men, ages 22-35). However, these are not the only option for social media today. The increasing number of features on Facebook is an advantage to all types of organizations that can benefit from online portals. "[Walt] Doyle [CEO of uLocate, a mobile location service] says that the experience on Facebook has to be very simple and devoid of commercialization. 'People are sensitive to corporate content,' he says, 'It's okay to be corporate if it is funny. Entertainment, fun, simple, and whimsical are all good." (Scott, 2007, P.235). All Facebook features such as pages, pictures, videos, events and applications should be easy to find and simple to use. Visibility and sharing capabilities are important for companies to get the attention and, ultimately, the retention of users.

\section{Chapter 4: Results and Recommendations}

Creating "An Effective social marketplace" is not easy, as discussed in the last few chapters; the digital media landscape is vast and malleable. A marketer's role in this landscape can also change almost instantly based on its audiences' behaviors.

The push and pull of online communications can be compared to a supply and demand model. There is a delicate balance between how much information organizations should supply and how much their audiences demand. At the same time, the marketer has to be the mediator in the middle by maintaining relationships with the consumers. An online social marketplace can also easily vary by industry or culture. The U.S.-based sites and businesses have international influences that must be considered as global borders fade. We conducted our survey between November and December 2011 to assess the current thoughts of Saudi Arabia internet users with regard to online marketing. In this time, 183 participants responded. Based on respondents' characteristics and the following charts show their demographic profile:

\section{Social Marketplace Survey Demographics:}

There is some indication of how current online demographics add up. Specifically, studies show that while 16-20 year olds consume a plethora of digital media (41\%), the online activity of users over 21 to 35 has been steadily increasing to reach $(38 \%)$.and that the majority are women, also we can see from the results that the highest percentage of members $(58.5 \%)$ level of education for High School, and there are (19.1\%) of the members of medium qualifications, and (3.3\%) owners of the qualification graduate. They provide a good insight as to the opinions of many different types of users across Saudi Arabia.

The goal of this survey was to gain insight on Saudi users' opinions of an organization's presence online and their internet behaviors with Facebook and other forms of social media. Additionally, the survey was designed to find the best ways a company can market to a consumer online according to the views of the intended audiences.

\section{Research Key Findings:}

In order to test the research hypothesis, we try to measure the relationship between the organization presence in Facebook and its marketing effectiveness; we use Pearson correlation between the organization presence in Facebook and its marketing effectiveness As follows:

\begin{tabular}{|l|l|l|c|l|l|}
\hline Variable & $\mathrm{N}$ & Mean & Std. Deviation & $\begin{array}{l}\text { Pearson } \\
\text { Correlation }\end{array}$ & Sig.(2-tailed) \\
\hline Build Customer relationship & 183 & 1.74 & .539 & $.687^{\star \star}$ & .000 \\
\hline Recognition or awareness & 183 & 1.54 & .500 & $.489^{\star \star}$ & .000 \\
\hline $\begin{array}{l}\text { Purchase decision or motivate } \\
\text { customers to buy }\end{array}$ & 183 & 1.49 & .501 & $.482^{\star \star}$ & .000 \\
\hline
\end{tabular}


**. Correlation is significant at the 0.01 level (2-tailed).

- The above table shows the relationship between the organization presence in facebook and its marketing effectiveness, and the results show that the relationship between the Organization's presence on Facebook and efficiency of the marketing relationship statistically significant at the level of significance $(0.01 \%)$ in each of the Build Customer relationship, Recognition or awareness, and Purchase decision or motivate customers to buy.

Saudi Consumers are spending almost their entire working day on the internet.

( $57.9 \%$ of respondents average $0-3$ hours per day online for personal use and $11.5 \%$ of respondents average $4-7$ hours per day for work or school-related activities, indicating some overlap for the majority of overall respondents.).

- High percentage of the internet users in the Saudi society are participating in the social networks beside many other uses of the internet:

Respondents could choose up to three primary uses of the internet. The following are the majority of highest-rated:

Email -41.0

Social networking -37.2

Reading news -31.7

Work -10.4

- $(65.0 \%)$ of the Internet users in the Saudi society think companies should be involved with social networks, $(64.5 \%)$ of the respondents active on Facebook agreed the site is a good platform for organizations to connect and form relationships with consumers.

- $(58.5 \%)$ of the Internet users in the Saudi society thinks that Facebook is good for companies to market their products and services, while (32.8\%) thinks that Facebook is good for companies to target the largest segment of consumers.

- $(54.1 \%)$ of the Internet users in the Saudi society thinks that organizations presence on the facebook encourage them to find out more about it or visit its website, and increase their awareness about the organization.

- $(49.2 \%)$ of the Internet users in the Saudi society thinks that organizations presence on the facebook encourage them to buy the company's products.

\section{Ideal Social Marketplace:}

The best online venue for organizations to reach its targeted consumers at this time lies in social networks. As demonstrated in the survey, there is a lot of activity in the social network realm. For instance, when questioned where they post photographs online, $(65.6 \%)$ of the total members of study sample do not add their photos online, and who add their photos on social networking sites, representing (26.2\%), and a share of the study sample who add their photos on Flickr representing (3.8\%).

This indicates that at least $26.2 \%$ of internet users in Saudi Arabia are active on social networks and very interactive within them. If they are posting pictures, they are likely looking at others' photos and may appreciate an organization's effort to display photographs or other content as well.

Research also shows that a large number of internet users think companies should use social networks. An impressive $65.0 \%$ of respondents agreed it is "a good idea" for companies to be present on these sites. Among this group, users believe it is beneficial to companies on the basis that it is a source of information about the companies; raises awareness of the organization and its issues, goals or products; a good way to market the products of the organization.

For most Saudi organizations, the results reveal that Facebook is the most ideal of the social networks. Because of the wide variety of users and the proven brand awareness and reliability, several types of industries could benefit from this new method for targeting consumers. Facebook allow for better social targeting than just banner advertisements. With the newsfeed, users can see what their friends are doing and their interests; also friends like what their friends like. If one sees that their friend is a fan of a certain entity, they would be more inclined to check it out. It is essentially "advertising with a social aspect."

According to the survey, $36.6 \%$ of respondents that use Facebook claimed they were frequent users ("frequent" was defined as visiting the site at least four times per week). Currently about $26.8 \%$ of Facebook users are signed up as fans of a public figure, object or organization through its Facebook page. Businesses and organizations need to find a way to guide more users to their pages or build more interaction with their Facebook page and other websites. 


\section{Recommendations}

\section{Recommendation \#1: mass media marketing is an option. But find new ways to do it.}

When the respondent were asked about the preferred way to market the products on the Internet, there are (36.6\%) said that the best way is to use advertising, there are (16.9\%) believe that the declaration in the social networking site is one of the best ways , while still $(13.7 \%)$ said that the use of e-mails is the best ways to market the company's products .So because that one of the most preferred method of online marketing to consumers is advertising, organizations should not dismiss it in their communication plans for the time being. On Facebook, organizations can buy banner ads displayed on the sides of a webpage, or social ads which are integrated within the site and in users' newsfeeds. As Holzner (2009) stated that technically, "social ads are placed in highly visible parts of the site without interrupting the user experience on Facebook. In other words, social ads are ads that attempt to get into the social conversation. Facebook connects them by reading the text of news feed items, for example."

Since Facebook is such a highly frequented network, advertising buys are extremely cheap compared to print or broadcast outlets, and can reach many more users. Yahoo!, for example, is adding a TV component to its toolbar so that as people are spending less time watching actual televisions, they can go online to watch programs while simultaneously surfing the web, increasing visibility of partnered companies or sponsors. Many companies are seeing the advantages of online advertising if done well. Social ads are arguably the easiest part of marketing. They must be creative and possibly have intricate technological or graphic capabilities but not much work needs to be done after that. Most advertisements do not require a further connection between the organization and the consumer. Marketers need to be attentive of the advertisement's design, placement and where it links. Advertisements now can even include video capabilities or links to an organization's Facebook Page from the home page. Marketers can also request that some Facebook users view their ads more often by using targeted recognition.

\section{Recommendation \#2: Use Facebook features that stimulate inclusiveness and display audio/visual elements.}

The graph below shows which Facebook features and applications that users find "effective" or "highly effective" for use by businesses. The top four elements emphasize inclusiveness (profile of the company, discussion board, audio/visual elements (videos and pictures). This is not surprising; it is has been repeatedly stated that users like relationships and feeling connected to companies and peers online. Being part of a group or an event's "guest list" is one way of doing this. Marketers can send updates and communicate with participants in both platforms through posting items, messages, or writing on the wall or discussion board.

In addition to inclusiveness, users are very interested in multimedia content. Only

$1 \%$ of survey respondents stated that they do not watch online videos from any site, while there are $(96.7 \%)$ watched video on YouTube, there are (20.7\%) watched video clips on the television network sites, and (2.2\%) watch video on news sites, and (4.9\%) watched the video on e-mail. suggests that the number of online users that do watch them is significant, even if not in social networks. Pictures and videos are available with almost all Facebook applications and should be utilized to communicate information, product details, exclusive content from events, messages from company representatives and more.

Recommendation \#3: Find the specific places where your target audiences interact and act as a content provider.

Chris Anderson (2008) argues that within any industry there are products that are "hits" and products that occupy "niches." He mentions that hits are those products that are widely known, and the niches are the products that are not very popular but they consumed enough so that at least one product is being purchased. Moreover, the niches get more markets than the hits and, because of that, they should be given more concern now a days. This applies to Facebook as well. Companies that have products or ideas including hits, niches, or both have the opportunity to market them on the site because of the wide variety of user interests to be found there. Anderson (2008) also goes with Weber's (2007) assumption that social media is made up of smaller, more focused networks that can benefit niche marketers. "Ultimately, marketing disappears if it does its job right... A manager of environment helps people make decisions to buy." (P.14).

Companies can start by scanning the environment where the targeted audiences interact on Facebook. By linking the previous recommendations with Saudi consumer behaviors, marketers will be able to customize messaging and content to appeal to them. Currently, the demographics differences between the intended audiences make the companies vary in their marketing ways to match the interests of their audiences.

Recommendation \#4: Create content that strongly supports the organization's brand or message, and keep it up to date.

Many organizations have creates pages and applications on Facebook that have floundered. How did this happen? This was happened because the pages was not updated or don't have content that attract fans or reflect company's personality. This is probably the most important part of any marketing process intended to keep the Saudi consumers 
interest and loyalty. Presenting an organization's goals, messages and public efforts are all part of showing the personality of the company and is a good way to stimulates fans and customers. "Branding is the dialogue you have with your customers and potential customers." (Weber, 2007, P. 97). Reinforcing this dialogue on Facebook can be fundamental to building credibility on the site and motivate Saudi users to be more interested with the organization's offers.

Moreover, most of the companies concern about the way that they should use it in interacting with the audience through network sites, should they be casual or should they maintain the professional way? However, this is something each organization must decide for itself based upon the company or brand's personality and the relationship it wants to have with consumers.

\section{The Changing Future:}

Speaking about the future, it's not easy to predict how the social marketplace will grow. Richer social media environment will work out, making it even more challenging for companies to gain the trust of consumers.

However, what seems certain is how the shift in online marketing is changing to a focus on smaller networks and niches. This will prove to be advantageous to small or midsize marketers in addition to the larger entities. (Weber, 2007). However, all companies will continue to adapt to changes as has been done in all forms of marketing for decades.

Outlook Recommendation: Continue to analyze online presence and consumer-generated content.

We can assess Saudi consumer trends by listening and getting involved with what these audiences are interesting in and what are they actually doing online. The best way to do this is to accurately analyze user feedback on Facebook and other social media sites such as blogs. By comparing Saudi consumer interests with improvements in technology and changes in the economy, this will lead us to the way the organizations should adapt to any new environments.

Looking ahead, the only thing that is certain is that "marketing on the Web will continue to evolve-quickly. Success comes from experimentation." (Scott, 2007, p.245). Obviously, what works now as the ideal social marketplace on Facebook will likely not be the best option five years from now.

\section{Research limitations:}

Although the research has reached its aim, there were some unavoidable limitations:

- First, because of time constraints, the research was conducted only on small size of population, therefore to generalize the results for larger group; the study should involve more participants.

- According to the limited number of libraries in saudi Arabia, we face so many difficulties in reaching the required references.

- Large segment of the Saudi society still don't have internet access, modem, and on-line service, and because of the slow network might discourage the participants interest and motivation in giving appropriate feedback through the internet, which cause us to receive few email response.

- Limitation of the time prevent us from enriching our research through using multiple data collection techniques and measurement types, such as (interview, market researches ... etc.).

- $\quad$ There are a limited number of researches that was conducted in the Saudi society about Facebook in general.

- Because of the Saudi's lack of knowledge about the researches importance in improving the way of living, and their wrong assumptions about the researchers, we faced some rejections from some people to fill our survey.

- The lack of communication between men and women in the Saudi society limited our ability of reaching the targeted number of males in responding to our survey.

- Because of the Saudi conservative society, some of the culture problems effects the response of the targeted segment, they weren't opened to answer some detailed questions about their behaviors and perceptions, because of the family obstacles and the society views.

\section{Conclusion}

Throughout the course of this research, the intended goal has been to determine if Facebook is an effective marketing tool in Saudi Arabia, and how organizations can use Facebook for marketing purposes. It was through several steps that the positive results were found.

In an intensive review of literature from multiple industry experts, it was found that there is a demand for social media marketing and the ideal social marketplace. Suggested strategies for community building and creating a successful presence in these online platforms showed that organizations must form relationships with consumers through transparency and a personable approach without overselling.

Since Facebook was hypothesized as the ideal platform for an organization in Saudi Arabia to create a social marketplace, and there is a relationship between Organization's presence on Facebook and the marketing effectiveness; a thorough breakdown of the site's features and environment was also necessary. Highlighted were some of the numerous applications available for organizations to capitalize on for marketing purposes. This portal offers more options for organizations to facilitate relationships with consumers than almost any other social media site.

Finally, an original survey was conducted to gain new information on the opinions of average internet users. It was concluded in the main findings that consumers are respectful of organizations online and recommend they get involved in 
social networks, Facebook especially. All of these results showed that the research was successful in finding how and where organizations and individuals can create an ideal social marketplace in the age of Web 2.0 and in preparation for the future. Research should advance on all of these topics as trends continue to change through all forms of digital media. The recommendations made here may not be applicable in five years, as recommendations made just five years ago may not be applicable now. More case studies should be drawn as results from current business endeavors become available while further analyses of Facebook and other social media sites should be done.

While the internet is changing rapidly, there are some recommendations made here that may be relevant for several years to come. The most long lived of these will no doubt be the need to create and maintain relationships with consumers on several social media platforms. While their opinions on advertising or Facebook groups may change, internet users will most likely continue to use multiple forms of communication for some time to come. Organizations that are able to navigate through these varied platforms and adapt their messages across them are more likely to thrive in the brave new world of online social media.

\section{Reference}

- Anderson, C. (2008). The Long Tail: Why the Future of Business is Selling Less of More. New York: Hyperion.

- Arrington, M. (2009). Facebook Now Nearly Twice the Size of MySpace Worldwide. TechCrunch. http://www.techcrunch.com/2009/01/22/facebook-now-nearly-twice-the-size-of-myspace- worldwide/

- Chaffey, D. \& Smith, P. R. (2005). eMarketing eXcellence: The heart of ebusiness (2nd ed.). Oxford: Elsevier Butterworth-Heinemann.

- Charlesworth, A. (2009). Internet marketing: A practical approach. Amsterdam: Elsevier ButterworthHeinemann. http://social.happytreefriends.com/group/chocolatefanclub

- Company History. YouTube. http://www.youtube.com/t/about.

- Davis, L. (2009). Does Facebook Replace Face Time or Enhance It?. Time Magazine. http://www.time.com/time/nation/article/0,8599,1871627,00.html?xid=rss-fullnation-yahoo

- Facebook Press Room. http://www.facebook.com/press.php.

- Gillin, P. (2009). Secrets of social media marketing: How to use online conversations and customer communities to turbo-charge your business. Fresno: Quill Driver Books.

- Helft, M. (2009). At First, Funny Videos. Now A Reference Tool. The New York Times.http://www.nytimes.com/2009/01/18/business/media/18ping.html? $\quad r=1$

- Holzner, S. (2009). Facebook Marketing: Leverage Social Media to Grow Your Business. United States: Que Publishing.

- Laudon, K. C. \& Traver, C. G. (2008). E-commerce: Business, technology, society (4th ed.). Upper Saddle River: Pearson/Prentice Hall.

- Linz. Thorsten. (2010). Universal McCann International Social Media Research Wave 5.http://www.slideshare.net/tlinz8612/wave-5-the-socialisation-of-brands-report-5465006.

- Lipsman, Andrew. (2008). Social Networking Explodes Worldwide as Sites Increase Their Focus on Cultural Relevance: comScore, Inc. http://www.comscore.com/press/release.asp?press=2396.

- MacManus, R. (2008). Facebook vs. Asia's Top Social Networks. ReadWriteWeb. http://www.readwriteweb.com/archives/facebook vs asia top social networks.php.

- Obermire, S. (2007). How Marketers Use Facebook.. RRW Consulting's Direct Marketing Blog. http://rrwdatabasemarketing.blogspot.com/2007/10/how-marketers-use-facebook.html.

- O'Reilly, T. (2005). What Is Web 2.0. O'Reilly Net. http://www.oreillynet.com/pub/a/oreilly/tim/news/2005/09/30/what-is-web-20.html.

- Popova, M. (2007). Poke Me, It's Real: Facebook, Interaction Benefits and the Future of Marketing: Brandweek.

- Schafer, I. (2009). Facebook's Changes Give Brands More Freedom. Advertising Age. http://adage.com/digitalnext/article?article id=135034.

- Schroeder, S. (2009). Facebook's Monetization Plan? Polls. And Lots of Them. Mashable: The Social Media Guide. http://mashable.com/2009/02/02/facebooks-monetization/

- Scott, D. (2007). The New Rules of Marketing \& PR. Hoboken: John Wiley \& Sons, Inc.

- Smith, J. (2009). Facebook's Redesigned Fan Pages to Compete More Directly with Twitter. Inside Facebook. http://www.insidefacebook.com/2009/03/03/facebooks-redesigned-fan-pages-to-competemoredirectly-with-twitter/

- Smith, J. (2009). How to Import Your Blog Into Facebook. Inside Facebook. http://www.insidefacebook.com/2009/02/22/how-to-import-your-blog-into-facebook/.

- Statistics. Facebook Press Room. http://www.facebook.com/press/info.php?statistics.

- Tuten, T. L. (2008). Advertising 2. O. Social media marketing in a web 2.0 world. Westport: Praeger 
- Weber, L. (2007). Marketing to the Social Web: How Digital Customer Communities Build Your Business. Hoboken: John Wiley \& Sons, Inc.

- World Tourism Organisation. (2008). Handbook on e-marketing: A practical guide for tourism destinations. Madrid: World Tourism Organisation.

- Zuckerberg, M. (2008). Facebook Across the Web. The Facebook Blog.

http://blog.facebook.com/blog.php?post=41735647130. 